\title{
Environmental influence on the phenotype of ant workers revealed by common garden experiment
}

\author{
Jessica Purcell ${ }^{1,2}$ (D) Dorin Pirogan ${ }^{1} \cdot$ Amaury Avril $^{1} \cdot$ Farid Bouyarden $^{1}$. \\ Michel Chapuisat ${ }^{1}$
}

Received: 13 October 2015 /Revised: 21 December 2015 / Accepted: 26 December 2015 /Published online: 15 January 2016

(C) Springer-Verlag Berlin Heidelberg 2016

\begin{abstract}
Many organism traits vary along environmental gradients. Common garden experiments provide powerful means to disentangle the role of intrinsic factors, such as genetic or maternal effects, from extrinsic environmental factors in shaping phenotypic variation. Here, we investigate body size and lipid content variation in workers of the socially polymorphic ant Formica selysi along several independent elevation gradients in Switzerland. We compare fieldcollected workers and workers sampled as eggs from the same
\end{abstract}

Communicated by L. Sundström

Significance statement When individuals show phenotypic variation along environmental gradients, is it shaped by the environment or by genes? To disentangle the contributions of phenotypic plasticity and local adaptation to trait variation, we reared ant brood from high and low elevations in common laboratory conditions. We then compared the body size and fat content of lab-reared and field-collected workers. Both size and fat content varied with elevation in field-collected workers, but the patterns differed among valleys. Lab-reared workers varied less than field-collected workers, indicating that size and fat content are largely shaped by environmental conditions. Overall, this experiment reveals that individual traits that generally co-vary with colony social structure in ants also depend upon the external environment.

Jessica Purcell and Dorin Pirogan contributed equally to this work.

Electronic supplementary material The online version of this article (doi:10.1007/s00265-015-2055-1) contains supplementary material, which is available to authorized users.

Jessica Purcell

jessica.purcell@ucr.edu; jessica.purcell@unil.ch

1 Department of Ecology and Evolution Biophore, UNIL-Sorge, University of Lausanne, 1015 Lausanne, Switzerland

2 Present address: Department of Entomology, University of California, Riverside, 900 University Avenue, Riverside, CA 92521, USA colonies but reared in common laboratory conditions. Overall, field-collected workers from high elevation are larger than those from low elevation, but the trend varies substantially among valleys. The same pattern is recovered when the eggs are reared in a common garden, which indicates that body size variation along elevation gradients and valleys is partly explained by genetic or maternal effects. However, both body size and lipid content exhibit significantly greater variation in field-collected workers than in laboratory-reared workers. Hence, much of the phenotypic variation results from a plastic response to the environment, rather than from genetic differences. Eggs from different elevations also show no significant difference in development time in the common garden. Overall, selection on individual worker phenotypes is unlikely to drive the altitudinal distribution of single- and multiplequeen colonies in this system, as phenotypic variation tends to be plastic and can be decoupled from social structure. This study provides insights into the interplay between individual phenotypic variation and social organization and how the two jointly respond to differing environmental conditions.

Keywords Adaptation - Elevation gradient · Eusociality · Body size $\cdot$ Formicinae $\cdot$ Formica selysi $\cdot$ Common garden

\section{Introduction}

Intraspecific trait variation plays a key role in many ecological and evolutionary processes. In most organisms, however, we know very little about whether polymorphic traits are predominantly heritable or whether trait variation results from a plastic response to the local environment. Elevation gradients provide an ideal opportunity to investigate the causes of trait variation (Partridge and Coyne 1997), because many environmental factors differ over short geographic distances. Although most 
research efforts in animals have focused on vertebrate species (e.g., Blackburn et al. 1999; Morrison and Hero 2003; Storz et al. 2010), insects also show extensive variation in morphological, behavioral, metabolic, physiological, and life history traits between populations living at low or high elevation (Block et al. 1990; Hodkinson 2005; Danks 2006).

Body size influences many physiological processes and fitness components and is probably the most studied trait along environmental gradients (Reichle 1968; McNab 1971; Blanckenhorn and Demont 2004). The predicted negative relationship between body mass and temperature, known as Bergmann's rule, has been found both across related species and within species (e.g., Partridge et al. 1994; Ashton 2002; Angilletta and Dunham 2003), but this pattern is not universal (McNab 1971; Mousseau 1997; Chown and Klok 2003; Blankenhorn and Demont 2004; Hodkinson 2005). When arthropods and other cold-blooded organisms follow Bergmann's rule, the pattern cannot be explained by the heat conservation mechanism proposed for endotherms. Instead, increasing body sizes in colder environments may be mediated by cell size (Van Voorhies 1996) or by selection for increased resistance to starvation (Cushman et al. 1993). Converse Bergmann's clines are also found in many arthropod taxa (Mousseau 1997), which might stem from the fact that short-season length and cold temperature constrain the development time required to reach a large body size (Partridge and Coyne 1997; Kocher et al. 2014).

A suite of factors, including development time and larval nutrition, contribute to adult body size in many arthropods (e.g., Fox and Czesak 2000; Kause et al. 2001; Sorvari and Hakkarainen 2009; Chown and Gaston 2010). The strong effect of the thermal environment on development time suggests that the latter is likely to be plastic (Abril et al. 2008, 2010). The brood's ability to accumulate fat reserves is also expected to be a complex function of intrinsic metabolic pathways (e.g., Arrese and Soulages 2010) and the food resources available to them, which may differ across environmental gradients (e.g., Tschinkel 1993; Kause et al. 2001). Lipid content of newly eclosed adults (a measure of larval nutrition) may be highly plastic but could also respond to differential selection under alternative environmental regimes (e.g., Warbrick-Smith et al. 2006). The social environment experienced during development, such as the presence or absence of maternal care in burying beetles, can also strongly influence both development time and lipid content (Rauter and Moore 2002). The extent to which phenotypes are shaped by genetic, environmental, and social factors can provide insights into whether trait variation results from genetic differences reflecting local adaptation to contrasted environmental conditions or whether it is primarily a plastic response to the environment.

In social insects, the social environment provided by caregiving workers can directly influence the phenotypes of brood (e.g., Linksvayer 2006; Purcell et al. 2012; Purcell and
Chapuisat 2014) or the environmental conditions experienced by colony members. For example, honeybees (Apis mellifera) regulate the ambient temperature and humidity inside their hive (e.g., Stabentheiner et al. 2003; Human et al. 2006). Hence, disentangling the relationships between colony-level social traits and individual phenotypes is challenging. Field et al. $(2010,2012)$ used a reciprocal transplant experiment to investigate the causes of solitary or social lifestyles and associated phenotypes in Halictus rubicundus. Transplanting foundresses from solitary northern populations to southern habitats that ordinarily harbor social populations and vice versa, they found that social structure and individual phenotypes (including body size) showed a plastic response to the environment. Whether this pattern is common in other systems remains an open question.

Our study organism, the Alpine silver ant Formica selysi, is an ideal species with which to investigate variation in individual phenotypes along environmental gradients. This ant is distributed throughout the Alps and Pyrenees in Europe, along a broad elevation gradient (Purcell et al. 2015). The species is socially polymorphic, with both single- and multiple-queen colonies (monogynous and polygynous, respectively) found together within populations (Chapuisat et al. 2004; Purcell and Chapuisat 2013). We recently discovered that the proportion of single-queen colonies increased at higher elevation, and this pattern was replicated across Alpine valleys populated by independent genetic lineages (Purcell et al. 2015). In $F$. selysi and in other ant species exhibiting a similar polymorphism in queen number, the two social forms differ in a suite of individual- and colony-level phenotypic traits, including colony size, relative investment in reproductive offspring, and individual body size (Rosset and Chapuisat 2006, 2007; reviewed by Keller 1995). Cross-fostering experiments of the eggs of monogynous and polygynous $F$. selysi queens revealed that intrinsic factors (genetic and/or parental effects) and the social environment provided by the caregiving workers shape some of the phenotypic traits associated with colony queen number (Meunier and Chapuisat 2009; Purcell and Chapuisat 2012, 2014). In addition, the recent discovery of a social chromosome with two genetically welldifferentiated haplotypes associated with monogynous and polygynous colonies provides indirect evidence that at least some of these phenotypic differences likely have a genetic basis (Purcell et al. 2014).

Here, we investigate how the phenotypic traits of individual ants vary along environmental gradients. We measured the head width (a good proxy for body size) and lipid content of workers collected from field populations at low and high elevations in several valleys. In complement, we performed a common garden brood-rearing experiment, using eggs collected from one low- and one high-elevation population in each of two valleys, to determine whether worker phenotypic differences are due to intrinsic factors (genetic and pre-foster 
maternal effects), to environmental conditions, or an interaction between the two. Since single-queen colonies make up a larger proportion of colonies at high elevation (Purcell et al. 2015) and tend to produce larger and fatter workers and queens (Schwander et al. 2005; Rosset and Chapuisat 2007), we expected workers from high-elevation populations to be larger and fatter overall. We hypothesized that this pattern might also occur when comparing monogynous colonies from high and low elevations and comparing polygynous colonies from high and low elevations. If the variation in studied traits depends on intrinsic factors, we expect persistent differences between individuals from different populations of origin, regardless of whether those individuals were sampled from the field or reared in common laboratory conditions. Such a pattern would suggest that worker size is genetically coupled to social form (or mediated through maternal effects) and that selection for larger body size at high elevation may indirectly favor single-queen societies. If, on the contrary, trait variation is due to a plastic response to environmental conditions, we expect to observe little difference in individuals originating from different populations that are reared under common laboratory conditions. This pattern would suggest that the mechanisms shaping individual phenotypes are independent from the factors influencing the distribution of social forms along elevation gradients. To our knowledge, this is the first study using a common garden approach to investigate adaptations to altitude in eusocial insects.

\section{Methods}

\section{Sampling}

F. selysi lives in the floodplains of mountain streams and rivers. In 2010-2011, we performed an initial field survey of head size differences along elevation gradients. We collected workers for head size measurement and microsatellite genotyping (see below). We sampled 8 workers from each of 4 to 12 colonies per population, in populations located at low and high elevations in three major Swiss river valleys, the Rhône, the Rhine, and the Maggia. The populations were located near Leuk, Valais $\left(7^{\circ} 36^{\prime}\right.$ $42^{\prime \prime} \mathrm{E}, 46^{\circ} 18^{\prime} 8^{\prime \prime} \mathrm{N}$, altitude $590 \mathrm{~m}$; 12 colonies); Les Haudères, Valais $\left(7^{\circ} 30^{\prime} 13^{\prime \prime} \mathrm{E}, 46^{\circ} 04^{\prime} 50^{\prime \prime} \mathrm{N}\right.$, altitude $1450 \mathrm{~m} ; 12$ colonies); Tamins, Graubünden, ( $9^{\circ} 24^{\prime} 30^{\prime \prime} \mathrm{E}$, $46^{\circ} 48^{\prime} 57^{\prime \prime} \mathrm{N}$, altitude $594 \mathrm{~m}$; 12 colonies); Safien, Graubünden $\left(9^{\circ} 19^{\prime} 8^{\prime \prime} \mathrm{E}, 46^{\circ} 40^{\prime} 54^{\prime \prime} \mathrm{N}\right.$, altitude $1281 \mathrm{~m} ; 12$ colonies); Maggia, Ticino ( $8^{\circ} 43^{\prime} 02^{\prime \prime}$ E, $46^{\circ} 13^{\prime} 56^{\prime \prime} \mathrm{N}$, altitude 305 m; 12 colonies); Peccia, Ticino ( $8^{\circ} 38^{\prime} 46^{\prime \prime}$ E, 46 $26^{\circ} 23^{\prime \prime}$ $\mathrm{N}$, altitude $820 \mathrm{~m} ; 8$ colonies); and Fusio, Ticino ( $8^{\circ} 39^{\prime} 47^{\prime \prime} \mathrm{E}$, $46^{\circ} 26^{\prime} 39^{\prime \prime} \mathrm{N}$, altitude $1240 \mathrm{~m}$; 4 colonies). Individuals from high and low elevations within each valley were collected on the same day, but the valleys were sampled at different times. The social structure of each colony (monogynous or polygynous) was inferred by genotyping eight workers per colony at eight polymorphic microsatellite markers (Chapuisat et al. 2004; Purcell et al. 2015).

In 2013, we collected workers and eggs for a common garden experiment (see below). We sampled individuals from colonies in one low- and one high-elevation population in each of two valleys, the Rhône and the Rhine. The two populations from the Rhine and the low-elevation population from the Rhône were the same as those described above, while the high-elevation Rhône population was located in Derborence, Valais $\left(7^{\circ} 13^{\prime} 53^{\prime \prime} \mathrm{E}, 46^{\circ} 17^{\prime} 17^{\prime \prime} \mathrm{N}\right.$, altitude $1377 \mathrm{~m}$ ). We assessed the social structure of these colonies by genotyping workers at three single-nucleotide polymorphisms (SNPs) that are diagnostic for the monogynous and polygynous social forms in our lowland Rhône population (Purcell et al. 2014). We verified that these markers are accurate for assessing colony social structure in other populations by comparing SNP and microsatellite results in at least five colonies per population (Table S1).

Between mid-June and mid-July, we collected fresh eggs from monogynous and polygynous colonies at both elevations in the Rhône valley, as well as from monogynous colonies at both elevations in the Rhine valley (Fig. 1). Polygynous colonies are rare at high elevation (Purcell et al. 2015), and we were not able to locate a sufficient number of polygynous colonies in the Rhine high-elevation population, so we only included eggs from monogynous colonies from this valley. As ant workers of this species readily accept and rear foreign eggs (e.g., Meunier and Chapuisat 2009; Purcell and Chapuisat 2012), we collected standard caregiving workers from six monogynous colonies at low elevation in the Rhône valley. Previous studies investigated how the background of caregiving workers influences brood phenotypes in this species (e.g., Meunier and Chapuisat 2009; Purcell et al. 2012; Purcell and Chapuisat 2012); in this study, we wanted to minimize the effect of caregiving workers and to focus on differences based on the origin of the eggs.

After the common garden experiment was completed, we collected five adult workers from egg-source field colonies (we collected these workers only in field colonies from which eggs successfully developed into adults in our laboratory experiment, so that we had both field-collected and laboratoryreared workers from the same field colonies). All workers were collected from 1 to 3 October 2013 and were frozen within $24 \mathrm{~h}$ of collection to avoid differences due to seasonal variation in collection date. We measured the head width and lipid content of these field collected workers and compared these measures to the ones of workers originating from the same colonies but reared in common laboratory conditions (see below).

\section{Common garden experiment}

Rearing groups (i.e., laboratory colonies, $n=108$ ) were composed of 50 eggs and 50 caregiving workers; the 1:1 


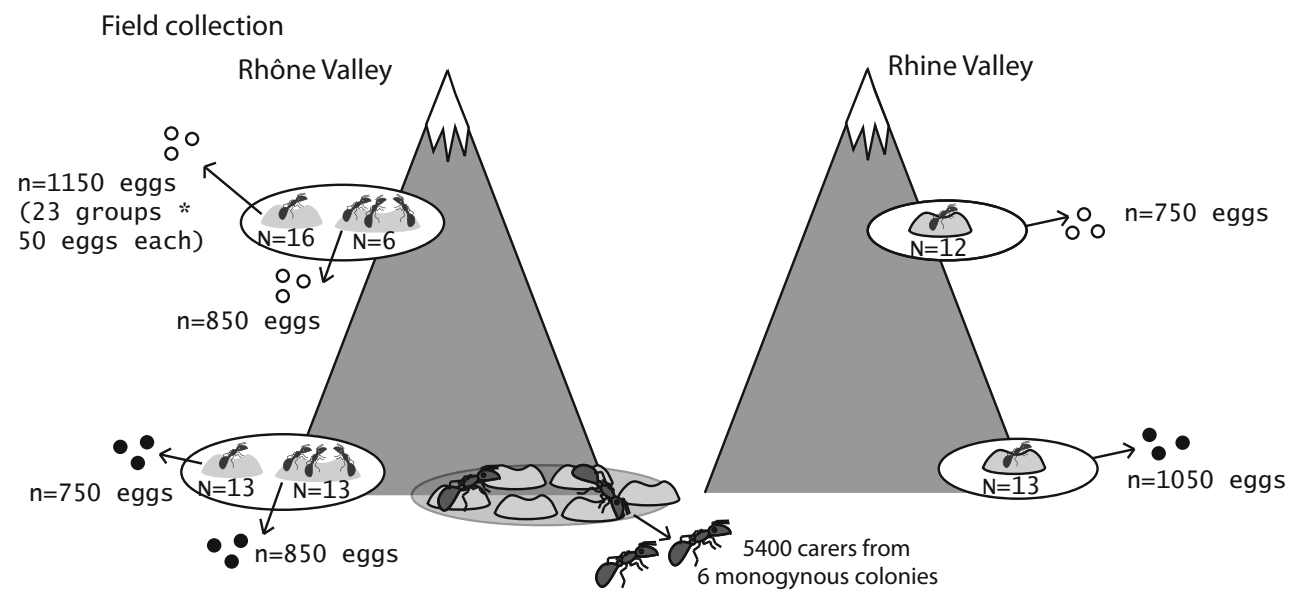

Common Garden

24 C, 63\% humidity, 12/12 light/dark cycle, standard care-giving workers
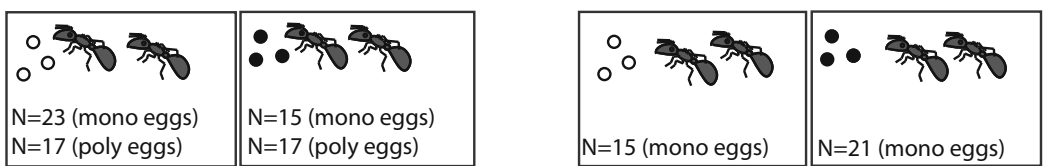

Rearing groups: 50 eggs, 50 (non-nestmate) care-giving workers

Fig. 1 Diagram showing the design for the common garden experiment. Eggs were collected from colonies at high and low elevations (eggs shown with white and black circles, respectively) from two valleys (Rhône and Rhine). " $N$ " shows the total number of monogynous (one ant symbol) and polygynous (three ant symbols) source colonies from each site, while " $n$ " represents the total number of eggs from each

worker:brood ratio ensures the best brood survival rate (Purcell et al. 2012). The carers originated from six field colonies, which were allocated equally to each treatment. An overview of the experimental design is provided (Fig. 1). The carers were placed in a plastic box $(15 \times 13 \times 5 \mathrm{~cm})$ side-lined with Fluon to prevent them from escaping. Fifty undamaged and non-parasitized eggs from one unrelated colony were added to each rearing group on a small, sterile petri dish. These eggs were collected after the sexual brood was produced in the field and contained no sexual offspring. The majority of the eggs were gathered immediately by the workers, as in previous experiments (Meunier and Chapuisat 2009; Purcell and Chapuisat 2012). Each rearing group had ad libitum access to food (consisting of agar, egg, honey, and a vitamin mix) and water. If a field colony provided enough eggs for two or three rearing groups (i.e., more than 100 or 150 non-parasitized eggs), eggs were placed in additional rearing groups, with carers from different colonies of origin.

Rearing groups were maintained in a climate-controlled chamber simulating the abiotic environment at low elevation, $24 \pm 0.5^{\circ} \mathrm{C}$ and $63 \%$ humidity (mean of monthly mean temperatures and monthly mean relative humidity from May to July registered from 1981 to 2010 at Sion, near our lowelevation Rhône site, at an altitude of $482 \mathrm{~m}$; data from the Federal Office of Meteorology and Climatology MeteoSwiss 2013). We used a 12:12-h light/dark cycle. Cold temperature population. Standard caregivers, depicted as the large grey workers, were collected from six monogynous colonies from a lowland population in the Rhône valley. The lower panel shows the composition of experimental groups in the common garden experiment, with eggs from the Rhône valley on the left and eggs from the Rhine valley on the right

conditions were also investigated (see supplementary materials).

We inspected the rearing groups two times per week for the first 2 weeks and every second day thereafter, noting the number of brood that remained and their development stage. Once the first larvae pupated, we monitored the rearing groups daily. When a new callow worker emerged, it was placed in a smaller plastic box $(10 \times 8 \times 4 \mathrm{~cm})$ with marked carers from the same rearing group. These workers were maintained with ad libitum access to water and food for 8 days. After this period, several phenotypic traits were measured. A total of 220 workers were successfully reared by 45 rearing groups -8 groups with eggs from the lower Rhône and from the upper Rhine, 14 from the lower Rhine, and 15 from the upper Rhône (average of five callow workers per successful rearing group, range of 1-16 workers/group).

\section{Phenotypic measures}

\section{Head size}

When newly emerged callow workers were 8 days old, we placed them at $-20{ }^{\circ} \mathrm{C}$ to euthanize them. We then measured head size, a good proxy for the overall body size (Wheeler 1991; Schwander et al. 2005), using a Leica S8AP0 microscope and the software LAS EZ version 2.0.0 (Leica 
Application Suite, Leica Microsystems, Wetzlar, Germany). We measured head width, from eye to eye, of 220 callow workers reared in the laboratory and of 190 workers collected from the same field colonies of origin as the lab-reared brood, in the same year (2013). The head width of the initial sample of 576 workers collected from field colonies in 2010-2011 was measured in the same way.

\section{Lipid content}

To evaluate the proportion of lipids, we followed the procedure described by Brand and Chapuisat (2012). We desiccated the corpses by keeping them at $62{ }^{\circ} \mathrm{C}$ for 8 days, measured the dry weight with a microbalance (Mettler Toledo MT5) and then kept each ant in $1 \mathrm{ml}$ of petroleum ether for $12( \pm 1)$ days to extract the lipids. We then dried the ants for 2 days at room temperature and 2 days at $62{ }^{\circ} \mathrm{C}$ and measured the lipid-free dry weight. The body lipid content was estimated as the difference between dry weight before lipid extraction and dry weight after lipid extraction. Lipid content and head size were measured using precise instruments and are unlikely to be influenced by observer bias. Nevertheless, callow workers from our common garden were cryptically labelled, so the observer could not distinguish treatments while he collected the data.

\section{Development time}

We measured brood development time from the egg-hatching date (which generally occurred within 1 day for each group of eggs) until the emergence of each individual as a callow worker.

\section{Statistical analysis}

To investigate differences between workers from low and high elevations, we constructed linear mixed-effect models, implemented in the "nlme" package (Pinheiro et al. 2015, R project software version 3.0.2; R Development Core Team 2013). For the individuals collected in 2010-2011, we included head width as the response variable, with the elevation, social structure, and valley of each colony of origin, plus the interactions between elevation and both social structure and valley, as fixed effects. We included the colony of origin as a random intercept.

The factors influencing the traits of the 2013 field-collected workers originating from the same colonies as the lab-reared brood were assessed with models in which the response variables were head size and lipid content, respectively. The fixed effects included elevation, social structure, and valley of each colony of origin, plus the interactions between elevation and both social structure and valley. The field colony of origin was included as a random intercept. We used a similar approach to measure the relationships between environmental factors (temperature and precipitation rate) and our focal traits (Table S2).

For the workers reared in common laboratory conditions, the response variables were head size, lipid content, and brood development time, respectively. The fixed effects were elevation, social structure, and valley of origin of eggs, the colony of origin of carers, plus the interactions between elevation and both social structure and valley. The identity of the laboratoryrearing group was included as a random intercept in the model. For all models, we assumed a Gaussian error structure and ensured that model assumptions were met. The residuals were normally distributed in all cases. We adjusted the alpha to control for multiple comparisons of the traits measured in lab-reared and 2013 field-collected workers, following the Bonferroni correction. In addition, we performed post hoc tests to determine whether there were significant differences between high- and low-elevation sites within each valley. For each variable, we also calculated Cohen's $d$ effect size and confidence intervals for both field-collected and lab-reared individuals.

\section{Results}

\section{Initial field survey}

In the initial survey of individual size differences along elevation gradients, field-collected workers from high-elevation populations were overall significantly larger than those from low-elevation populations. However, this association of body size with elevation varied across valleys, being present in the Rhine and Maggia valleys but not in the Rhône valley (full model $F_{(1,459)}=19016, p<0.001$; elevation $F_{(1,64)}=16.9$, $p<0.001$; interaction between elevation and valley $F_{(2}$, ${ }_{64)}=13.5, p<0.001$; Fig. 2). There were also significant differences between social forms, with individuals from monogynous colonies being larger (social structure $F_{(1,64)}=26.1$, $p<0.001)$. There was no interaction between elevation and social structure on body size $\left(F_{(1,64)}=1.26, p=0.266\right)$. Average summer and winter temperatures and annual precipitation rates were also highly correlated with elevation, and head size was greater in colder environments and in wetter environments, although this pattern was driven by differences in the Rhine and Maggia valleys and was not present in the Rhône valley (Table S2 and Fig. S1). Moreover, some populations exhibited greater variance in worker body size than others (supplementary materials).

\section{Field-collected versus laboratory-reared workers}

Workers sampled from the field colonies that supplied eggs for the common garden experiment were significantly larger at 
Fig. 2 Formica selysi workers from high-elevation populations are significantly larger than those from low-elevation populations in two out of three valleys. Horizontal bars for each valley show the results of post hoc tests. The boxplots show the median values and the upper and lower quartiles. The whiskers encompass 1.5 times the interquartile range. The circles represent average head sizes for each colony; white and grey circles indicate monogynous and polygynous colonies, respectively

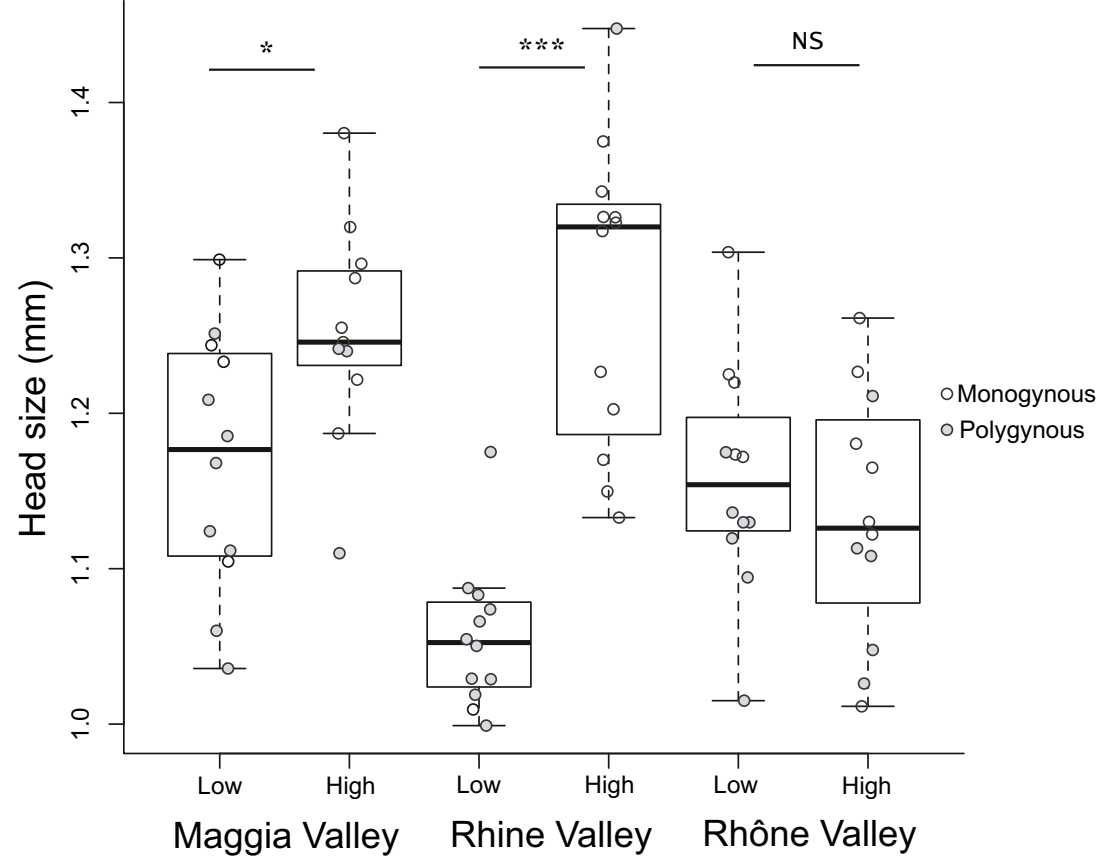

higher elevation in the Rhine valley but not in the Rhône valley (Fig. 3 and Table 1). This was reflected in the significant interaction between elevation and valley. Consistent with previous findings, workers from monogynous colonies were larger, on average, than workers from polygynous colonies (Schwander et al. 2005; Table 1). Interestingly, there was no difference between the head size of workers from the high- and low-elevation populations in the Rhône valley in both 2010-2011 and 2013, with two separate high-elevation populations analyzed.

The head size of newly eclosed workers reared in the common garden depended upon whether the eggs originated from low- or high-elevation populations and upon their valley of origin (Table 1). In the common garden, the workers originating from the high population in the Rhine valley reached a
Fig. 3 Worker head size and lipid content measures for fieldcollected (a, b) and lab-reared (c, d) workers. The provenance of individuals from high- and lowelevation populations in the Rhine (left side of the panels) and Rhône (right side of the panels) valleys is shown on the $x$ axis. As shown in Fig. 2, the boxplots show the median values and the upper and lower quartiles. The whiskers encompass 1.5 times the interquartile range, but in this figure, the circles represent outliers. Horizontal bars for each valley show the results of post hoc tests
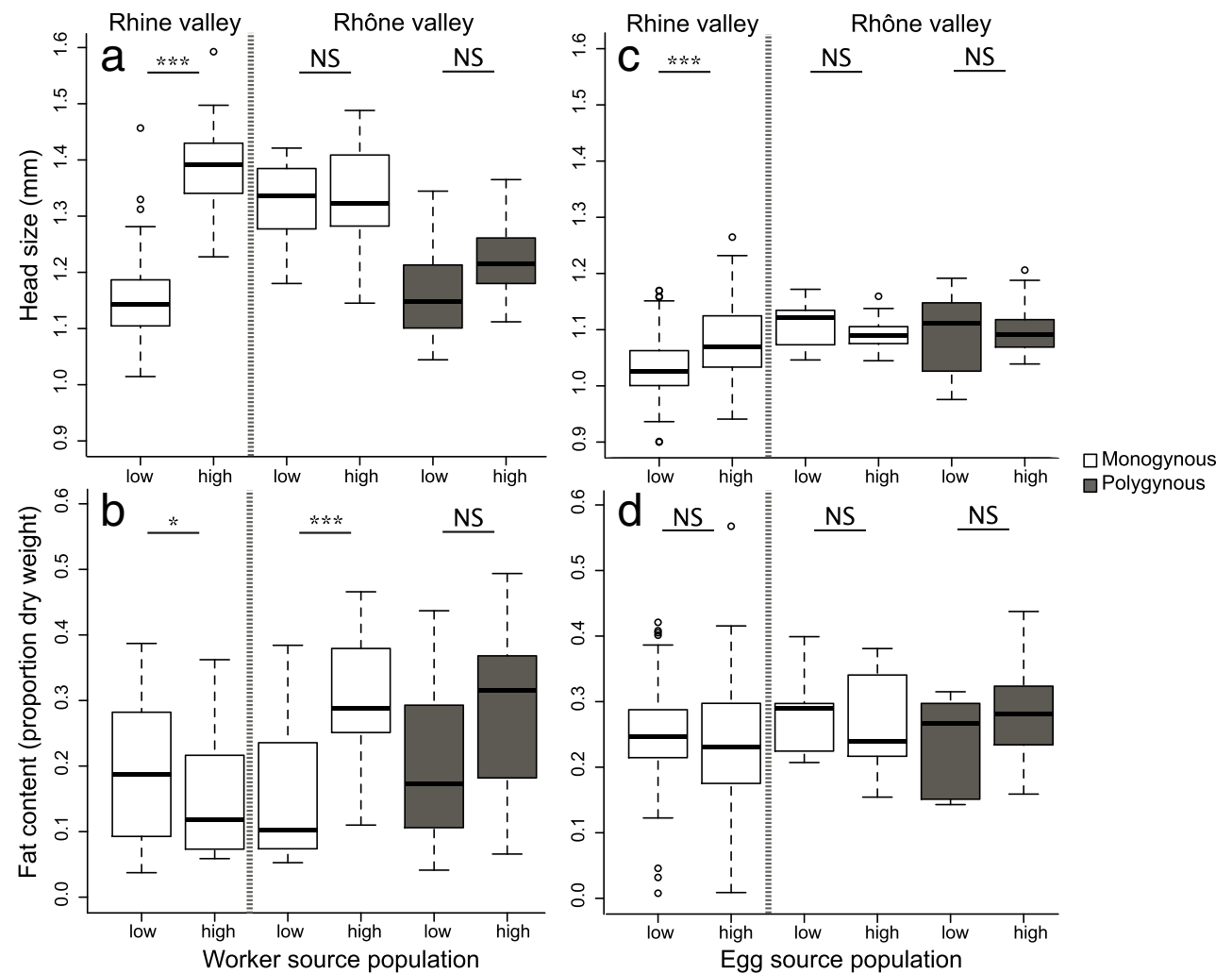
Table 1 Statistical results from linear mixed-effect models for field-collected and lab-reared workers

\begin{tabular}{|c|c|c|c|c|c|}
\hline & \multicolumn{2}{|l|}{ Field collected } & \multicolumn{3}{|c|}{ Reared in common laboratory conditions } \\
\hline & Head size $(\mathrm{mm})$ & Lipid content & Head size (mm) & Lipid content & Development time \\
\hline Full model & $\begin{array}{l}F_{(1,152)}=17946 \\
p<0.001\end{array}$ & $\begin{array}{l}F_{(1,152)}=311 \\
p<0.001\end{array}$ & $\begin{array}{l}F_{(1,168)}=29519 \\
p<0.001\end{array}$ & $\begin{array}{l}F_{(1,170)}=1623, \\
p<0.001\end{array}$ & $\begin{array}{l}F_{(1,170)}=2853 \\
p<0.001\end{array}$ \\
\hline Elevation & $\begin{array}{l}F_{(1,32)}=51.4 \\
p<0.001\end{array}$ & $\begin{array}{l}F_{(1,32)}=3.07 \\
p=0.089\end{array}$ & $\begin{array}{l}F_{(1,35)}=8.09 \\
p=0.007\end{array}$ & $\begin{array}{l}F_{(1,35)}=0.335 \\
p=0.566\end{array}$ & $\begin{array}{l}F_{(1,35)}=0.004 \\
p=0.952\end{array}$ \\
\hline Social structure & $\begin{array}{l}F_{(I, 32)}=15.2 \\
p=0.001\end{array}$ & $\begin{array}{l}F_{(1,32)}=2.24 \\
p=0.115\end{array}$ & $\begin{array}{l}F_{(1,35)}=1.92, \\
p=0.175\end{array}$ & $\begin{array}{l}F_{(1,35)}=1.14 \\
p=0.293\end{array}$ & $\begin{array}{l}F_{(1,35)}=1.29 \\
p=0.264\end{array}$ \\
\hline Valley & $\begin{array}{l}F_{(1,32)}=9.00 \\
p=0.005\end{array}$ & $\begin{array}{l}F_{(1,32)}=3.89 \\
p=0.057\end{array}$ & $\begin{array}{l}F_{(1,35)}=5.78 \\
p=0.022\end{array}$ & $\begin{array}{l}F_{(1,35)}=1.64 \\
p=0.208\end{array}$ & $\begin{array}{l}F_{(1,35)}=0.145 \\
p=0.706\end{array}$ \\
\hline Carer origin & NA & NA & $\begin{array}{l}F_{(4,35)}=1.11, \\
p=0.366\end{array}$ & $\begin{array}{l}F_{(4,35)}=2.85 \\
p=0.038\end{array}$ & $\begin{array}{l}F_{(4,35)}=1.27 \\
p=0.299\end{array}$ \\
\hline Elevation $\times$ social structure & $\begin{array}{l}F_{(I, 32)}=5.85 \\
p=0.022\end{array}$ & $\begin{array}{l}F_{(1,32)}=0.752, \\
p=0.392\end{array}$ & $\begin{array}{l}F_{(1,35)}=0.819 \\
p=0.372\end{array}$ & $\begin{array}{l}F_{(1,35)}=2.58 \\
p=0.118\end{array}$ & $\begin{array}{l}F_{(1,35)}=0.040 \\
p=0.843\end{array}$ \\
\hline Elevation $\times$ valley & $\begin{array}{l}F_{(1,32)}=21.2 \\
p<0.001\end{array}$ & $\begin{array}{l}F_{(1,32)}=11.3 \\
p=0.002\end{array}$ & $\begin{array}{l}F_{(1,35)}=2.25 \\
p=0.142\end{array}$ & $\begin{array}{l}F_{(1,35)}=0.127 \\
p=0.723\end{array}$ & $\begin{array}{l}F_{(1,35)}=0.584 \\
p=0.450\end{array}$ \\
\hline
\end{tabular}

Due to multiple comparisons, we adjusted the $\alpha$ to 0.025 for the models of field-collected workers and to 0.017 for models of laboratory-reared workers. Significant effects are emphasized in bold italic font

larger adult size than the ones originating from the low population in the same valley (Fig. 3). In contrast, workers originating from the high and low populations in the Rhône valley showed little variation in head width (Fig. 3). There was no significant difference in head size based upon the social structure of the colony of origin of eggs or upon the colony of origin of the caregiving workers. Moreover, neither interaction term had a significant impact on head size (Table 1). Importantly, the difference in head size between workers originating from high and low populations was significantly smaller for workers reared in common laboratory conditions, as compared to field-collected workers (Fig. 3 and Table 2).

The lipid content of field-collected workers showed a significant interaction between elevation and valley, with fatter workers found in high-elevation populations in the Rhône and the reverse pattern occurring in the Rhine valley populations (Fig. 3 and Table 1). Other factors had no significant impact on lipid content (Table 1).

The lipid content of workers reared in the common garden did not differ significantly across elevation, social structure, or valley of origin of eggs (Fig. 3 and Table 1). The colony of origin of carers had a marginally non-significant effect on lipid content, after correction for multiple comparisons. The magnitude of the difference in lipid content between workers originating from low- and high-elevation populations was far smaller for workers reared in the common laboratory conditions, as compared to field-collected workers (Fig. 3 and Table 2).

There was no significant difference in development time (measured from egg hatching until emergence of callow worker) between eggs collected from high- and low-elevation populations and reared in the common garden (Table 1 and Fig. 4). We also found no difference in development time between eggs from different valleys or those from monogynous and polygynous colonies (Table 2). Further, the colony of origin of the carers had no significant effect on development time.

Table 2 Cohen's $d$ effect sizes for comparisons of head size, lipid content, and development time, with $95 \%$ confidence intervals shown in square brackets and ranges in parentheses

\begin{tabular}{|c|c|c|}
\hline Cohen's $d$ & Field & Laboratory \\
\hline \multicolumn{3}{|l|}{ Development time } \\
\hline \multicolumn{3}{|c|}{ High versus low origin } \\
\hline Rhine & & $-0.383[-1.834,1.067]$ \\
\hline Rhône & & $0.258[-1.782,2.299]$ \\
\hline Rhine versus Rhône & & $-0.105[-1.381,1.170]$ \\
\hline $\begin{array}{l}\text { Polygynous versus } \\
\text { monogynous } \\
\text { (Rhône) }\end{array}$ & & $0.361[-1.664,2.386]$ \\
\hline Carers (range) & & $-0.6(-1.46,0.29)$ \\
\hline \multicolumn{3}{|l|}{ Head size } \\
\hline \multicolumn{3}{|l|}{ High versus low origin } \\
\hline Rhine & $4.520[4.497,4.543]$ & $0.999[0.978,1.020]$ \\
\hline Rhône & $0.470[0.432,0.508]$ & $-0.370[-0.381,-0.359]$ \\
\hline Rhine versus Rhône & $-0.184[-0.218,-0.149]$ & $-0.998[-1.010,-0.986]$ \\
\hline $\begin{array}{l}\text { Polygynous versus } \\
\text { monogynous } \\
\text { (Rhône) }\end{array}$ & $-2.410[-2.436,-2.384]$ & $-0.393[-0.403,-0.382]$ \\
\hline Carers (range) & & $0.3(-0.15,0.78)$ \\
\hline \multicolumn{3}{|l|}{ Lipid content } \\
\hline \multicolumn{3}{|c|}{ High versus low origin } \\
\hline Rhine & $-0.664[-0.691,-0.637]$ & $-0.197[-0.219,-0.176]$ \\
\hline Rhône & $1.538[1.506,1.570]$ & $0.391[0.370,0.412]$ \\
\hline Rhine versus Rhône & $-0.765[-0.790,-0.740]$ & $-0.205[-0.219,-0.190]$ \\
\hline $\begin{array}{l}\text { Polygynous versus } \\
\text { monogynous } \\
\text { (Rhône) }\end{array}$ & $0[-0.043,0.043]$ & $-0.186[-0.208,-0.164]$ \\
\hline Carers (range) & & $0.32(-0.45,0.74)$ \\
\hline
\end{tabular}


Fig. 4 Development time in common laboratory conditions did not differ among eggs collected from high and low elevations or from monogynous (white) and polygynous (grey) colonies. Horizontal bars for each valley show the results of post hoc tests

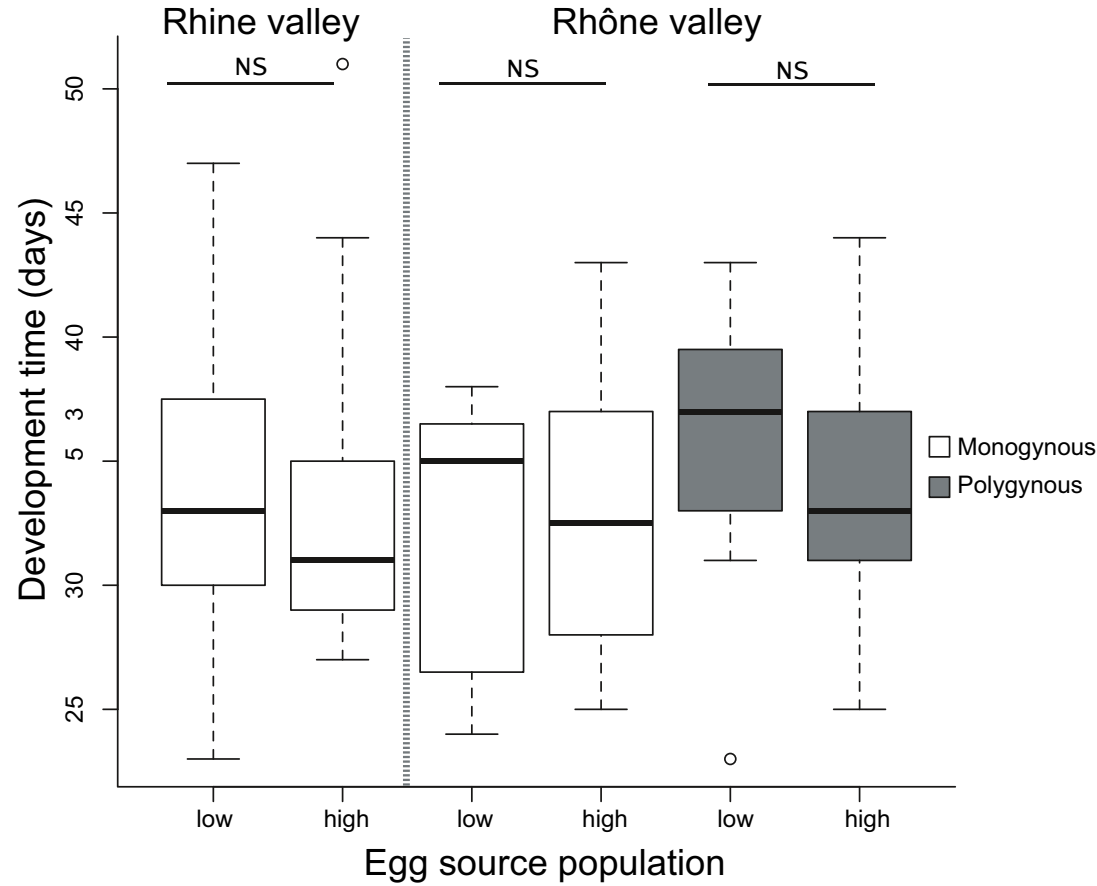

\section{Discussion}

Field-collected ant workers had significantly larger head sizes at higher elevation in some valleys but exhibited no size difference in others. This pattern was recovered in lab-reared individuals, which indicates that variation in body size along elevation gradients and across valleys is partly explained by genetic differences or maternal effects and might thus reflect some degree of local adaptation. The magnitude of the effect was much greater in field-collected workers, however, suggesting that the environment experienced during development plays a major role in shaping adult size. With respect to lipid content, field-collected workers from high elevation were fatter than those from low elevation in the Rhône valley, and the opposite pattern was observed in the Rhine valley. In contrast, workers reared in common laboratory conditions showed no significant difference in lipid content. The fact that head size and lipid content were much less variable in the common garden than in the field indicates a high degree of phenotypic plasticity in these traits.

Can these patterns shed light on the factors shaping the consistently higher proportion of monogynous colonies at high elevation in F. selysi (Purcell et al. 2015)? We hypothesized that selection for larger body sizes at higher elevation could contribute to this pattern, since individuals of monogynous origin tend to be larger. However, the high degree of plasticity in head size revealed by the common garden experiment shows that individual size can be largely decoupled from social structure. This finding, combined with the variable patterns in the distribution of body size across different valleys, suggests that selection on worker size and genetic correlations linking body size to social structure are unlikely to be strong enough to influence the altitudinal distribution of monogynous and polygynous colonies in this species. In a similar vein, we previously observed that monogynous brood have a quicker development and a faster growth rate than polygynous ones (Purcell and Chapuisat 2012). We hypothesized that this could provide an advantage to monogynous colonies at higher elevation, where colonies face shorter-growing seasons (Kocher et al. 2014). In the common garden, however, the development time from egg hatching until adult emergence did not differ between eggs sampled at low versus high elevation, suggesting that intrinsic differences in offspring development time are unlikely to drive the distributions of alternative social structures. Thus, genetic constraints on the worker traits that we measured in this system (body size, lipid content, and development time) seem unlikely to play a direct role in shaping the distribution of monogynous and polygynous colonies. Future studies should investigate whether the traits of queens show a higher degree of local adaptation than those of workers (e.g., Bargum et al. 2004).

Our study also shows that the social chromosome haplotypes associated with queen number variation in one population (Purcell et al. 2014) are also present and associated with queen number in other populations (Table S1). This finding means that the frequency of the Sm (monogyne-associated) haplotype increases as the proportion of monogynous colonies increases at higher elevation. Thus, although we previously found little genetic differentiation at microsatellite markers between high- and low-elevation populations from the same valley (Purcell et al. 2015), there are still average genetic differences between populations from different elevations at the social chromosome. These social chromosome haplotypes are evolving under different average conditions, pointing to 
the possibility of local adaptation in traits not measured in the present study.

Altitudinal clines in both head size and lipid content differed across the two valleys and social structures. In particular, the size of field-collected workers was significantly larger at higher elevation in monogynous colonies from the Rhine valley but not in monogynous colonies from the Rhône valley. Along the same lines, the interaction between elevation and valley had a significant impact on lipid content, which was greater at higher elevation in the Rhône valley but not in the Rhine valley. This variation demonstrates that the response to elevation differs among populations within the same species and emphasizes the need to replicate studies of trait variation along independent environmental gradients (Kawecki and Ebert 2004). Similarly, variable patterns have been identified in other arthropod groups (Chown and Klok 2003). In the $F$. selysi system, we previously documented genetic differentiation between valleys, based on microsatellite markers (Purcell et al. 2015). To the extent that the differences in worker phenotypes were maintained in the common garden (and thus shaped by genetic or maternal effects), this pattern could therefore be shaped by genetic drift or by local adaptation to factors not measured in the present study that may differ among valleys, such as the parasite pressure, competition, diet composition, or soil type.

Our results, which focus on intraspecific variation along elevation gradients, are consistent with previous findings on interspecific and intraspecific variations in ant body size along latitudinal gradients (Cushman et al. 1993). Ant workers tend to be larger in colder environments (e.g., Heinze et al. 2003). A previous common garden experiment on Myrmica rubra sampled across latitudinal gradients revealed that much of the variation in lipid content is likely a response to environmental conditions (Elmes et al. 1999). In these studies, the authors suggested that differences in the background of the caregiving workers could also influence worker phenotypes. Indeed, caregiving workers from different elevations and populations may differ in their allocation of resources to brood, and the contrasting environments provided by these caregivers may drive the phenotypic variation among field-collected workers. Interestingly, even with standard carers collected from six monogynous colonies from the same population, we observed a marginally non-significant effect of the colony of origin of carers on the lipid content of lab-reared workers. This may indicate intercolony variation in brood-feeding rates, a possibility that was not tested in our experiment. Thus, follow-up experiments investigating differences in brood care provided by workers from varying environments could yield more insights into the causes of phenotypic differences among fieldcollected workers (supplementary materials).

In ectotherms, the relative importance of fixed genotypic differences reflecting local adaptation versus phenotypic plasticity in determining trait variation along environmental gradients is poorly understood. Our results indicate a large degree of phenotypic plasticity in body size, which is in line with several hypotheses. First, the pattern of larger body size in cold environments may be simply a by-product of the effect of temperature on cellular growth, with no adaptive value (Van Voorhies 1996). Other non-adaptive processes could also produce this pattern; for example, the worker-to-brood ratio in ant colonies influences body size and may differ among populations and between social forms (Purcell et al. 2012).

Alternatively, phenotypic plasticity in body size may be adaptive and selection may favor different developmental responses to alternative conditions (Partridge and Coyne 1997; Angilletta et al. 2004). In non-social animals, larger body size in colder environments is expected to improve fecundity, longevity, dispersal and migration abilities, and resistance to starvation (Partridge and Coyne 1997; Angilletta et al. 2004). In eusocial species, fecundity and dispersal abilities are primarily important for queens, which also tend to have a stronger genetic control of body size than workers (Bargum et al. 2004; Meunier and Chapuisat 2009; Haatanen and Sorvari 2013). For workers, increased longevity and resistance to starvation associated with larger body size may be relatively more important in harsh environments at higher elevation (Cushman et al. 1993; Heinze et al. 2003).

Common-garden experiments are used on a wide range of organisms to determine whether phenotypic variation observed in nature is genetically determined or plastic (e.g., Broggi et al. 2005; Rutter and Fenster 2007; Field et al. 2012). In our experiment, we found that environmental conditions experienced during development play a major role in shaping size and lipid content of ants, while social structure, elevation, and valley of origin of eggs play a minor role. Hence, traits that are likely to influence the functioning and success of ant colonies show a high degree of phenotypic plasticity. Whether this variation is adaptive deserves further investigation.

Acknowledgments We thank Alan Brelsford and two anonymous reviewers for their comments on the manuscript, as well as Timothée Brütsch and Nayuta Brand for their assistance in the field and in the lab. This project was funded by Swiss National Science Foundation grants 31003A-125306 and 31003A-146641 to MC.

\section{References}

Abril S, Oliveras J, Gómez C (2008) Effect of temperature on the oviposition rate of Argentine ant queens (Linepithema humile Mayr) under monogynous and polygynous experimental conditions. J Insect Physiol 54:265-272

Abril S, Oliveras J, Gómez C (2010) Effect of temperature on the development and survival of the Argentine ant, Linepithema humile. J Insect Sci 10:1-13 
Angilletta MJ Jr, Dunham AE (2003) The temperature-size rule in ectotherms: simple evolutionary explanations may not be general. Am Nat 162:332-342

Angilletta MJ Jr, Steury TD, Sears MW (2004) Temperature, growth rate, and body size in ectotherms: fitting pieces of a life-history puzzle. Integr Comp Biol 44:498-509

Arrese EL, Soulages JL (2010) Insect fat body: energy, metabolism, and regulation. Annu Rev Entomol 55:207-225

Ashton KG (2002) Patterns of within-species body size variation of birds: strong evidence for Bergmann's rule. Glob Ecol Biogeog 11:505523

Bargum K, Boomsma JJ, Sundström L (2004) A genetic component to size in queens of the ant, Formica truncorum. Behav Ecol Sociobiol 57:9-16

Blackburn TM, Gaston KJ, Loder N (1999) Geographic gradients in body size: a clarification of Bergmann's rule. Divers Distrib 5:165-174

Blanckenhorn WU, Demont M (2004) Bergmann and converse Bergmann latitudinal clines in arthropods: two ends of a continuum? Integr Comp Biol 44:413-424

Block W, Baust JG, Franks F, Johnston IA, Bale J (1990) Cold tolerance of insects and other arthropods. Philos T Roy Soc B 326:613-633

Brand N, Chapuisat M (2012) Born to be bee, fed to be worker? The caste system of a primitively eusocial insect. Front Zool 9:35

Broggi J, Orell M, Nilsson J (2005) Local adaptation to winter conditions in a passerine spreading north: a common-garden approach. Evolution 59:1600-1603

Chapuisat M, Bocherens S, Rosset H (2004) Variable queen number in ant colonies: no impact on queen turnover, inbreeding, and population genetic differentiation in the ant Formica selysi. Evolution 58: 1064-1072

Chown SL, Gaston KJ (2010) Body size variation in insects: a macroecological perspective. Biol Rev 85:139-169

Chown SL, Klok JC (2003) Altitudinal body size clines: latitudinal effects associated with changing seasonality. Ecography 26:445-455

Cushman JH, Lawton JH, Manly BFJ (1993) Latitudinal patterns in European ant assemblages: variation in species richness and body size. Oecologia 95:30-37

Danks HV (2006) Insect adaptations to cold and changing environments. Can Entomol 138:1-23

Development Core Team R (2013) R: a language and environment for statistical computing. R Foundation for Statistical Computing, Vienna

Elmes GW, Wardlaw JC, Nielsen MG, Kipyatkov VE, Lopatina EB, Radchenko AG, Barr B (1999) Site latitude influences on respiration rate, fat content, and the ability of worker ants to rear larvae: a comparison of Myrmica rubra (Hymenoptera: Formicidae) populations over their European range. Eur J Entomol 96:117-124

Federal Office of Meteorology and Climatology MeteoSuisse (2013) Climate normals Sion: reference period 1981-2010. http:/www. meteosuisse.admin.ch/files/kd/climsheet/en/SIO_norm6190.pdf Accessed June 10, 2013

Field J, Paxton R, Soro A, Bridge C (2010) Cryptic plasticity underlies a major evolutionary transition. Curr Biol 20:2028-2031

Field J, Paxton R, Soro A, Craze P, Bridge C (2012) Body size, demography and foraging in a socially plastic sweat bee: a common garden experiment. Behav Ecol Sociobiol 66:743-756

Fox CW, Czesak ME (2000) Evolutionary ecology of progeny size in arthropods. Annu Rev Entomol 45:341-369

Haatanen M-K, Sorvari J (2013) Similarity of body size in queens of the wood ant Formica aquilonia from optimal and sub-optimal habitats indicates a strong heritable component. J Insect Sci 13:1-11

Heinze J, Foitzik S, Fischer B, Wanke T, Kipyatkov VE (2003) The significance of latitudinal variation in body size in the Holarctic ant, Leptothorax acervorum. Ecography 26:349-355

Hodkinson ID (2005) Terrestrial insects along elevation gradients: species and community responses to altitude. Biol Rev 80:489-513
Human H, Nicolson SW, Dietemann V (2006) Do honeybees, Apis mellifera scutellata, regulate humidity in their nest? Naturewissenschaften 93:397-401

Kause A, Saloniemi I, Morin JP, Haukioja E, Hanhimäki S, Ruohomäki K (2001) Seasonally varying diet quality and the quantitative genetics of development time and body size in birch feeding insects. Evolution 55:1992-2001

Kawecki TJ, Ebert D (2004) Conceptual issues in local adaptation. Ecol Lett 7:1225-1241

Keller L (1995) Social life: the paradox of multiple-queen colonies. Trends Ecol Evol 10:355-360

Kocher SD, Pellissier L, Veller C, Purcell J, Nowak MA, Chapuisat M, Pierce NE (2014) Transitions in social complexity along elevational gradients reveal a combined impact of season length and development time on social evolution. P Roy Soc Lond B 281:20140627

Linksvayer TA (2006) Direct, maternal and sibsocial genetic effects on individual and colony traits in an ant. Evolution 60:2552-2561

McNab BK (1971) On the ecological significance of Bergmann's rule. Ecology 52:845-854

Meunier J, Chapuisat M (2009) The determinants of queen size in a socially polymorphic ant. J Evol Biol 22:1906-1913

Morrison C, Hero JM (2003) Geographic variation in life-history characteristics of amphibians: a review. J Anim Ecol 72:270-279

Mousseau TA (1997) Ectotherms follow the converse to Bergmann's rule. Evolution 51:630-632

Partridge L, Coyne JA (1997) Bergmann's rule in ectotherms: is it adaptive? Evolution 51:632-635

Partridge L, Barrie B, Fowler K, French V (1994) Evolution and development of body size and cell size in Drosophila melanogaster in response to temperature. Evolution 48:1269-1276

Pinheiro J, Bates D, DebRoy S, Sarkar D, R Core Team (2015). nlme: linear and nonlinear mixed effects models. $\mathrm{R}$ package version 2.1 120, http://CRAN.R-project.org/package=nlme.

Purcell J, Chapuisat M (2012) The influence of social structure on brood survival and development in a socially polymorphic ant: insights from a cross-fostering experiment. J Evol Biol 25:2288-2297

Purcell J, Chapuisat M (2013) Bidirectional shifts in colony queen number in a socially polymorphic ant population. Evolution 67:11691180

Purcell J, Chapuisat M (2014) Foster carers influence brood pathogen resistance in ants. P Roy Soc Lond B 281:20141338

Purcell J, Brütsch T, Chapuisat M (2012) Effects of the social environment on the survival and fungal resistance of ant brood. Behav Ecol Sociobiol 66:467-474

Purcell J, Brelsford A, Wurm Y, Perrin N, Chapuisat M (2014) Convergent genetic architecture underlies social organization in ants. Curr Biol 22:2728-2732

Purcell J, Pellissier L, Chapuisat M (2015) Social structure varies with elevation in an Alpine ant. Mol Ecol 24:498-507

Rauter CM, Moore AJ (2002) Quantitative genetics of growth and development time in the burying beetle Nicrophorus pustultus in the presence and absence of post-hatching parental care. Evolution 56: $96-110$

Reichle D (1968) Relation of body size to food intake, oxygen consumption, and trace element metabolism in forest floor arthropods. Ecology 49:538-542

Rosset H, Chapuisat M (2006) Sex allocation conflict in ants: when the queen rules. Curr Biol 16:328-331

Rosset H, Chapuisat M (2007) Alternative life-histories in a socially polymorphic ant. Evol Ecol 21:577-588

Rutter MT, Fenster CB (2007) Testing for adaptation to climate in Arabidopsis thaliana: a calibrated common garden approach. Ann Bot 99:529-536

Schwander T, Rosset H, Chapuisat M (2005) Division of labour and worker size polymorphism in ant colonies: the impact of social and genetic factors. Behav Ecol Sociobiol 59:215-221 
Sorvari J, Hakkarainen H (2009) Forest clear-cutting causes small workers in the polydomous wood ant Formica aquilonia. Ann Zool Fenn 46:431-438

Stabentheiner A, Pressl J, Papst T, Hrassnigg N, Crailsheim K (2003) Endothermic heat production in honeybee winter clusters. J Exp Biol 206:353-358

Storz J, Scott GR, Cheviron ZA (2010) Phenotypic plasticity and genetic adaptation to high-altitude hypoxia in vertebrates. J Exp Biol 213: 4125-4136
Tschinkel WR (1993) Sociometry and sociogenesis of colonies of the fire ant Solenopsis invicta during one annual cycle. Ecol Monogr 63:425-457

Van Voorhies WA (1996) Bergmann size clines: a simple explanation for their occurrence in ectotherms. Evolution 50:1259-1264

Warbrick-Smith J, Behmer ST, Lee KP, Raubenheimer D, Simpson SJ (2006) Evolving resistance to obesity in an insect. P Natl Acad Sci USA 203:14045-14049

Wheeler DE (1991) The developmental basis of worker caste polymorphism in ants. Am Nat 138:1218-1238 